\title{
HIV and COVID-19: Lessons From HIV and STI Harm Reduction Strategies
}

\author{
Ronnie M. Gravett ${ }^{1,2}$ (D) Jeanne M. Marrazzo ${ }^{1}$ \\ Accepted: 18 May 2021 / Published online: 8 June 2021 \\ (C) This is a U.S. government work and not under copyright protection in the U.S.; foreign copyright protection may apply 2021
}

\begin{abstract}
Purpose of Review This review highlights the intersection of the COVID-19, HIV, and STI pandemics and examines how harm reduction strategies can be applied broadly to controlling a pandemic.

Recent Findings Since the onset of the COVID-19 pandemic, remarkable advances in the understanding of COVID-19 prevention, diagnosis, and treatment have been made at a much faster pace than prior pandemics, yet much more still remains to be discovered. Many of the strategies to control the COVID-19 pandemic mirror those employed to stem the HIV pandemic.

Summary Harm reduction principles used in the HIV pandemic can be applied to reduce the morbidity and mortality of the COVID-19 pandemic through effective prevention, detection, and treatment strategies.
\end{abstract}

Keywords COVID-19 $\cdot$ HIV $\cdot$ Sexually transmitted infections $\cdot$ Harm reduction $\cdot$ SARS-CoV-2

\section{Introduction}

In the summer of 1981, the first published reports of young gay men falling ill with an uncommon pneumonia heralded the start of the HIV pandemic [1, 2]. In late 2019, reports emerged from Wuhan, China, about a new, severe respiratory illness [3]. Less than a year later, the world was again overwhelmed by a new pathogen causing substantial morbidity and mortality. The outbreak of Severe Acute Respiratory Syndrome Coronavirus 2 (SARS-CoV-2) that began in late 2019 has now spread across the globe. At the time of this writing, over 25 million cases and nearly 450,000 deaths have occurred in the United States, and, globally, over 100 million cases and over 2.2 million deaths have been reported [4, 5]. While early public interventions such as masking, distancing,

This article is part of the Topical Collection on Co-infections and Comorbidity

Ronnie M. Gravett rgravett@uabmc.edu

1 Division of Infectious Diseases, Department of Medicine, University of Alabama at Birmingham, 1900 University Blvd, THT 215, Birmingham, AL 35294, USA

2 Birmingham Veterans Administration Medical Center, Birmingham, AL, USA and shutdowns were employed to a variable extent, SARSCoV-2 quickly overcame the collective ability to contain it. Although notably deadly, this pathogen's ability to spread significantly among asymptomatic and presymptomatic individuals quickly hampered public health and medical professionals' ability to respond. This asymptomatic spread, similar to the transmission of HIV, allows SARS-CoV-2 to spread stealthily, often announcing itself after many exposures. In fact, several attributes of the COVID-19 pandemic mirror those of the early HIV epidemic.

Lessons learned from past pandemics should inform future pandemics, but what happens when two (or more) pandemics intersect? COVID-19 has emerged at a time when HIV and sexually transmitted infections (STIs) continue to prove a major public health burden, causing significant morbidity and mortality. During the current COVID-19 public health crisis, competing priorities with limited resources have impacted HIV and STI care. Simultaneously, COVID-19 may also have affected the HIV and STI epidemics. Strategies used in early epidemic control for HIV and STI were similar to those initially employed to control the SARS-CoV-2 outbreak. Such strategies, rooted in public health control measures and harm reduction, are broadly applicable to containing any infectious pathogen [6].

Classically associated with substance use disorders, harm reduction strategies aim to mitigate the adverse outcomes associated with a behavior without necessarily requiring that 
individuals stop engaging in the behavior. In the case of HIV and STIs, harm reduction improves sexual health by preventing and treating HIV and STIs without asking that people abstain from having sex. Harm reduction principles can thus be translated to help slow the COVID-19 pandemic. This review will discuss the interplay between the COVID-19 and HIV and STI pandemics through a harm reduction lens and highlight how harm reduction strategies mitigate the risk of both COVID-19 and HIV/STI.

\section{COVID-19 Impact on HIV and Sexual Healthcare}

The COVID-19 pandemic disrupted our ability to provide comprehensive HIV primary care, including sexual health care, to those persons in greatest need. Prior to the COVID19 pandemic, the HIV epidemic in the United States was experiencing modest downtrends due in part to successful harm reduction strategies, such as HIV pre-exposure prophylaxis (PrEP), as well as increasing testing to identify new cases, improving linkage to care, and more convenient and tolerable dosing of antiretroviral (ART) therapy [7]. Early COVID-19 mitigation strategies affected our ability to provide prompt, in-person care, leading to a tremendous shift to virtual medicine platforms, including telephone and video telemedicine [8]. This transition allowed care to continue for many, highlighting a new avenue for ongoing care [9]. It also accentuated the inequities and may have worsened disparities due to lack of means to participate in virtual care, such as a capable device, internet access, or technology literacy. Many HIV and sexual health clinics halted their in-person visits, interrupting the care continuum for HIV as well as limiting access to inperson sexual health services for STI screening and management [10-12]. The abrupt shift to telemedicine allowed care to continue, but there were declines in linkage and retention in HIV care, antiretroviral starts, and viral suppression rates at HIV clinics in the USA and globally [13, 14]. Equally important, reagents needed for STI diagnostic testing were diverted to SARS-CoV-2 assays in this public health crisis, undermining availability to offer basic diagnostic tests for chlamydia and gonorrhea. While it remains to be seen how these measures affect the HIV and STI epidemics, it is quite possible, and even likely, that the COVID-19 pandemic will reduce recent progress made.

Most data to date show that persons living with HIV (PLWH) do not have significantly increased susceptibility to COVID-19. Early case series and case-control studies did not show a significant difference in mortality among PLWH, but more recent data from larger population-based cohorts in the USA and Europe has shown trends towards higher COVID-19 mortality among PLWH. [15-26] These trends are especially notable among PLWH who also have co-morbidities that increase the risk for severe COVID-19 and among racial and ethnic minorities. [20, 22-24, 27] At this time, data are mixed to truly associate HIV status with adverse outcomes due to COVID-19; rather, it is much more evident that disparate COVID-19 outcomes are more strongly associated with cardiovascular and metabolic comorbidities and being of racial or ethnic minority status, which are more common among PLWH [28].

\section{Harm Reduction in Principle}

Harm reduction, broadly defined, prioritizes minimizing the harm caused by an action or a behavior over stopping the action or behavior [29]. Critically, harm reduction recognizes the contribution of stigma related to a behavior and aims to reduce this stigma as a barrier to improving health. This approach has been applied most commonly to substance use, such as tobacco use, alcohol use, and injection drug use. Recognizing that substance abuse behaviors lead to adverse health outcomes, the primary goal of harm reduction is to prevent or slow the social and physical harms associated. Harm reductionists often apply these principles to halting the spread of a pathogen. Indeed, HIV and other STI management have also benefited from harm reduction strategies [30].

If SARS-CoV-2 acquisition and subsequent COVID-19 disease is the adverse outcome to avoid, then what is the behavior or action to minimize to reduce this harm? Undoubtedly, this a difficult question. Merely being near other persons can lead to virus transmission through respiratory droplets and even possibly airborne particles, but complete social isolation is not only impractical but almost impossible. Identifying the harms to minimize must be considered in the broader context that recognizes individual physical and mental health.

\section{Harm Reduction Strategies}

Harm reduction strategies for infectious diseases are relatively similar and can correlate from pathogen to pathogen. Indeed, in the case of COVID-19, HIV, and STIs, many of the same principles for harm reduction can be transposed, although with different details [31, 32].

\section{Prevention}

Intuitively, preventing an adverse outcome is ideal. Multiple biomedical and behavioral strategies exist to reduce harm by either stopping exposures, modifying exposures, or preventing acquisition after exposure. 


\section{Barrier Protection}

Condoms reduce transmission of HIV and bacterial STIs effectively, if used adequately and consistently, but lack of access to condoms or perhaps even personal preference limits their utility. As a correlate to barrier protection, masking has proven effective to reduce the expulsion of SARS-CoV-2 and other respiratory virus droplets [33-36]. Early in the pandemic, the role of masking was not certain, and the lack of available personal protective equipment (PPE) reinforced tendencies towards inadequate or no masking. Consistent masking remains one of the most effective ways of reducing transmission, especially in close contact, such as hair salons and airplane flights [37-40]. Multiple concentrated outbreaks have been linked to activities without mask use, such as choir practice, playing close contact sports, and children's summer camp without masks, highlighting the relative ease of transmission without enforced masking or distancing [41-43]. Although a nationwide mask mandate in the United States has been implemented only for certain circumstances, several US states have adopted broader measures, which have been associated with decreased spread of SARS-CoV-2 and declines in hospitalization rates among persons aged 18-64. [44-47] Among healthcare workers (HCWs) in one US healthcare system, a mask mandate significantly reduced new virus acquisition after its implementation [48]. Additionally, concurrent social distancing recommendations to stay at least $6 \mathrm{ft}$. or $1 \mathrm{~m}$ apart as well as "shelter-in-place" orders, also referred to as lockdowns or shutdowns, have drastically altered the course of the pandemic in states and countries that have employed these measures. These types of "shelter-in-place" restrictions do not align with harm reduction truly, as the defined harm in COVID-19 is exposure to the virus via contact with other persons. Nevertheless, it remains effective, just as abstinence is effective at preventing HIV and STIs, but permanent abstinence, or long-lasting shutdowns in the case of COVID-19, is not practical, despite their clear short-term effectiveness.

\section{Chemoprophylaxis}

Established biomedical HIV prevention strategies, such as PrEP and post-exposure prophylaxis (PEP), have shown incredible ability to reduce HIV acquisition at the individual level as well as some protection at the population level to reduce HIV acquisition. PrEP with combination oral tablets, emtricitabine combined with either tenofovir disoproxil fumarate $(\mathrm{F} / \mathrm{TDF})$ or tenofovir alafenamide $(\mathrm{F} / \mathrm{TAF})$, as well as newer agents such as long-acting cabotegravir injections effectively reduce sexual HIV acquisition by nearly $100 \%$ if taken adequately [49-52]. For SARS-CoV-2, multiple observational studies and randomized, controlled clinical trials have shown no benefit to hydroxychloroquine (HCQ) as PrEP or
PEP [53-57]. Further, no data support the use of vitamin C, vitamin D, or zinc as PrEP for SARS-CoV-2 infection [58•].

\section{Vaccination}

While an effective HIV vaccine remains elusive, multiple phase 3 clinical trials are ongoing to evaluate SARS-CoV-2 vaccines. Similarly, vaccine development against Neisseria gonorrhoeae, Chlamydia trachomatis, and Treponema pallidum is also proceeding. Vaccination for preventing HIV and STIs has yet to demonstrate robust protection against infection, but vaccination against SARS-CoV-2 to prevent COVID-19 looks to be the most promising route for prevention. Several vaccine candidates have demonstrated considerable efficacy. The first two vaccine candidates, BNT162b2 and mRNA-1273, use innovative messenger ribonucleic acid (mRNA) platforms. These mRNA vaccines employ lipid nanoparticles to introduce mRNA into host cells for the host ribosomes to then create the spike protein which is the antigen target for the adaptive immune response. These have demonstrated remarkable efficacy at preventing severe COVID-19 and good tolerability [59-61]. Administered in a two-dose regimen 21 days apart, Pfizer/BioNTech's BNT162b2 vaccine showed $95 \%$ efficacy to protect against COVID-19 among 36,523 participants with no prior COVID-19 in a large, multinational clinical trial. The primary endpoint was symptomatic COVID-19 confirmed by polymerase chain reaction (PCR). No severe COVID-19 cases were identified in the vaccine arm. The BNT162b2b vaccine was very safe and fairly well tolerated. Among the BNT162b2 recipients, $83 \%$ reported a local, injection site reaction after their first dose, and $78 \%$ reported a reaction after the second dose; most were mild to moderate and resolved within 1-2 days. There were few serious adverse events in either arm, and there were no deaths related to the vaccine $[61 \bullet]$. The BNT162b2 vaccine requires $-80{ }^{\circ} \mathrm{C}$ storage. While large medical facilities may have the resources to store this vaccine, cold chain transport and need for expensive, $-80^{\circ} \mathrm{C}$ freezers significantly limits its ability to be rolled out broadly. The other mRNA vaccine, mRNA- 1273 produced by Moderna, similarly showed considerable efficacy and safety. Also administered in a two-dose regimen, although 28 days apart, the mRNA-1273 vaccine showed $94.1 \%$ efficacy at preventing COVID-19 among 30,420 participants in a large, randomized clinical trial in the USA. Also, there were no severe COVID-19 in the vaccine intervention arm. Similarly, mild to moderate local and systemic reactogenic symptoms were much frequent in the mRNA-1273 participants, but the serious adverse events were rare [60]. Unlike the BNT162b2 vaccine, the mRNA-1273 vaccine does not require such low temperatures for freezing yet still requires cold chain transport and subzero freezers for storage. At the time of this writing, these two mRNA vaccines have been granted Emergency Use Authorization (EUA) by 
the US Federal Drug Administration (FDA). Other vaccine candidates, which are employing more traditional, although potent, viral vectors, are currently undergoing phase 3 clinical trials. Interim results for three candidates appear promising to offer fairly good efficacy and tolerability. In phase 1-2a trials, Janssen's Ad26.COV2.S vaccine (or JNJ-78436735) against SARS-CoV-2 demonstrated high production of neutralizing antibody in over $90 \%$ of participants on day 29 after the first dose and approached $100 \%$ by day 57 [62]. Early results from the phase 3 ENSEMBLE trial report $72 \%$ efficacy in the USA and $66 \%$ efficacy overall in preventing moderate to severe COVID-19 28 days after a single dose of the vaccine as well as $85 \%$ efficacy in preventing severe disease across all multinational study sites [63]. Perhaps the most promising aspect of this vaccine candidate is that it is administered as a single dose and can be transported through standard vaccine distribution channels. The As26.COV2.S may not be as effective as the mRNA vaccine, but it still offers protection from severe COVID-19 while improving ease of implementation and roll-out. In early, interim analysis, Astra Zeneca's ChAdOx1 nCoV-19 (AZ1222), another two-dose regimen dosed at least 4 weeks apart (although up to 12 weeks), showed efficacy in protecting against symptomatic COVID-19 by $66.7 \%$ with no severe COVID-19 cases in the vaccine arm among participants in Brazil, South Africa, and the United Kingdom [64]. "Sputnik V" is the nicknamed adenovirus vector vaccine, Gam-COVID-Vac. Interim results from a large phase 3 trial showed $91.6 \%$ efficacy in reducing PCR-confirmed COVID19 after two doses 21 days apart in among 21,977 participants in Russia [65].

As vaccination efforts increase in the community, the need to reach communities of color, especially Black/African American, Hispanic/Latinx, and Native and Indigenous communities, demands equitable implementation [66]. Analogous to HIV PrEP, systemic and structural barriers such as few vaccination sites, requirement for online registration, and vaccine hesitancy may prevent at-risk persons from being vaccinated $[67,68]$. These barriers must be addressed in all implementation plans to ensure that vaccine access is fair and equitable to all communities.

\section{Detection}

Another major tenet of harm reduction in infectious diseases is early detection. While early intervention is actually the key in reducing adverse outcomes, detection early in the course is necessary in order to then perform the intervening treatment. Laboratory methods for detecting HIV, STIs, and SARS-CoV-2 infection are similar, but there are key differences in understanding the utility of diagnostic methods due to the different syndromes, and different timelines, that each of these causes.

\section{Nucleic Acid Amplification Test}

Nucleic acid amplification testing (NAAT), most often performed by reverse transcriptase polymerase chain reaction (RT-PCR), detects a pathogen's presence by identifying and amplifying unique nucleic acid sequences or genes of a particular pathogen. Often, NAATs are the most sensitive and specific tests for identifying a pathogen. HIV RNA detection in blood, termed viral load, is not the sole means of identifying infection, but it is the most sensitive and specific. In fact, the viral load is used to monitor response to ART. Similarly, most STIs can be diagnosed by performing a NAAT on a specimen obtained from the site of exposure (oropharynx, urethra, cervix, vagina, or anus) to identify pathogens such as C. trachomatis, N. gonorrhoeae, Trichomonas vaginalis, Mycoplasma genitalium, and herpes simplex virus (HSV). Notably, syphilis cannot currently be diagnosed by NAAT unless it is applied to a genital ulcer (chancre) caused by T. pallidum. Both HIV and STI diagnostics have evolved with tremendous gains in achieving both highly sensitive and highly specific assays.

NAAT is the current main method to diagnose SARSCoV-2 infection, and these tests can use upper airway samples, such as nasopharyngeal swabs and mid-turbinate swabs, and lower airway samples, such as sputum and bronchoalveolar lavage (BAL) fluid. NAATs from nasopharyngeal swabs and BAL offer the high sensitivity and specificity [69•]. While the majority of these tests require specialized equipment, training, and long turn-around time, some NAATs are available in a rapid platform using loop-mediated isothermal amplification (LAMP) with fair sensitivity while retaining excellent specificity when standard, lab-based NAATs are not available. [69•]

\section{Antigen}

Antigen testing offers a method for quickly diagnosing acute infections in a point-of-care (POC) or laboratory setting. In the case of HIV, p24 antigen detection indicates recent infection and is useful for diagnosing HIV prior to the development of antibodies, i.e., relatively shortly after HIV acquisition. For COVID-19, antigen testing diagnoses acute infections rapidly among symptomatic persons by most often detecting the nucleocapsid protein ( $\mathrm{N}$ protein) from nasal or nasopharyngeal swabs. This rapid diagnosis attribute sacrifices some degree of sensitivity while maintaining fairly robust specificity, although some variability among tests are noted [70]. The Abbott BinaxNOW Ag Card (Abbott Laboratories, Scarborough, ME) performed fairly well among individuals with high viral loads by comparison PCR with cycle threshold (Ct) less than 30, showing a sensitivity of $93.3 \%$ and specificity of $99.9 \%$ [71]. In a real-world analysis at community health centers, this assay showed excellent specificity when 
compared to PCR but did have considerably lower sensitivity among both symptomatic (64.2\%) and asymptomatic (35.8\%) persons among all participants regardless of SARS-CoV-2 viral load [72]. In multiple analyses, these rapid assays maintained high levels of specificity when compared to RT-PCR, but the sensitivity declined considerably, especially among asymptomatic persons. Moreover, the sensitivity seems to be lower in samples with higher $\mathrm{Ct}$ values. As such, the utility of rapid antigen testing is highest with a positive result, but its utility is diminished with negative test results in individuals with a consistent COVID-19 syndrome, justifying a secondstep RT-PCR assay [73-75].

\section{Serology}

Antibody detection, whether IgA, IgM, or IgG, only confirms prior exposure. This limits its utility in detecting acute infection, but not necessarily current infections as is the case in HIV. In the case of HIV and syphilis, serology is a useful method for screening asymptomatic persons because infections with these pathogens are chronic (assuming syphilis remains untreated). Currently, there is no widely accepted role for screening serology for detecting acute SARS-CoV-2 infection, largely because the antibodies that confer enduring protection are not necessarily assayed in commercially available tests [76]. This situation may change as the pandemic evolves.

\section{At-Home Testing}

Testing from the ease and comfort of home is relatively recent approach to increase access for persons who otherwise may not be able to or feel comfortable pursuing HIV testing or sexual health services, and it can be an important tool for harm reduction [77]. For HIV, home testing can employ oral swab to detect HIV antibodies and give a rapid result at home, or a fingerstick blood sample can be collected and mailed in to be tested in a lab. These tests offer good sensitivity and excellent specificity. For STIs, increasing availability of at-home, mailin testing offers another avenue for screening and diagnosis. Since stigma is a major barrier to accessing HIV and STI health services, at-home testing reduces that barrier and can provide peace of mind to individuals concerned about their sexual health but unable to readily access these services.

At-home testing for SARS-CoV-2 allows a person who may have COVID-19 to remain isolated at home, thus helping to prevent the spread of SARS-CoV-2 as well as allowing the person to remain at home if they are not feeling well enough to travel. Athome testing platforms include at-home collection kits to be mailed back and assayed in a lab to receive a result and also inhome test kits that will give a result in the home. At-home test kits are available by prescription using LAMP molecular techniques or over the counter using antigen detection as a lateral flow assay from self-collected mid-turbinate nasal swabs. When compared to FDA-authorized lab-based NAATs, these tests have good positive percent agreement (PPA) and negative percent agreement (NPA) among symptomatic persons with slightly lower PPA and NPA among asymptomatic persons. For the Lucira COVID-19 All-InOne Test Kit (Lucira Health, Emeryville, CA), which uses LAMP to identify SARS-CoV-2 RNA, the PPA and NPA were $94.1 \%$ and $98.0 \%$, respectively, and PPA increased to $100 \%$ when cycle threshold values decreased to less than $37.5[78,79]$. For the Abbott BinaxNOW COVID-19 Ag Card Home Test (Abbott Laboratories, Scarbourough, ME), PPA and NPA were $91.7 \%$ and $100 \%$, respectively, among symptomatic persons within 7 days of symptom onset [80, 81]. The Ellume COVID-19 Home Test (Ellume, Queensland, AUS), a lateral flow assay to detect nucleocapsid antigen, reports an overall PPA and NPA of 95\% and $97 \%$, respectively. Among symptomatic persons, the PPA and NPA were slightly higher at $96 \%$ and $100 \%$, respectively, but PPA and NPW were slightly lower among asymptomatic persons at $91 \%$ and $96 \%$, respectively [82-84]. A common thread among these at-home tests is that they perform better among symptomatic persons, earlier in their course, and with higher viral load (lower $\mathrm{Ct}$ values). These data reassure that home testing is a valuable approach to reduce need for healthcare access, but real-world performance data for these at-home assays are limited to date.

\section{Treatment}

Treating the condition is perhaps the most direct principle of harm reduction, in this case, treating the SARS-CoV-2 infection to reduce the harm of COVID-19 disease, i.e., the morbidity and mortality. Early initiation with antiretrovirals (ARV) against HIV significantly improves the morbidity and mortality with HIV; in fact, standard of care is to offer antiretroviral therapy (ART) as soon as possible after diagnosis [85]. Not only does early ART initiation improve outcomes for the individual, it also prevents sexual transmission once the individual has a suppressed viral load. Undoubtedly, safe, tolerable, and effective ART is the most important advancement in HIV care. Similar treatment interventions for COVID19 are not yet available, although some agents do offer mortality benefit as well as improved recovery time. Supportive care for mild to moderate COVID-19 remains the mainstay of therapy, but passive immunity with monoclonal antibodies has shown benefit in reducing progression to more severe disease. For more ill persons, further treatment options include antivirals, immune modulators, and corticosteroids [58•].

\section{Monoclonal Antibody}

Monoclonal antibodies $(\mathrm{mAb})$ for treating infections are relatively new to our antimicrobial armamentarium. Ibalizumab is the first $\mathrm{mAb}$ available for treating HIV in persons with multidrug resistant HIV, and its utility comes as salvage therapy 
for heavily treatment experienced PLWH. [86]. More recent$\mathrm{ly}, \mathrm{mAb}$ are currently in clinical trials for HIV prevention, although interim analysis does not show robust protection from HIV acquisition.

For COVID-19, mAb have been examined for prevention of COVID-19 as well as treatment along the clinical spectrum. Bamalanivimab is a mAb directed against the SARS-CoV-2 spike protein that decreases viral shedding, improves symptoms, and reduces hospitalizations among non-hospitalized persons not requiring oxygen, but there was no benefit seen in hospitalized patients. [87-90] Furthermore, this benefit was also accentuated when combined with etesevimab as a "cocktail," demonstrating $70 \%$ risk reduction in hospitalizations or mortality in early results announced by press release [91, 92]. Bamalanivimab as monotherapy as well as combination with etesevimab have been granted EUA by the FDA [93]. Another $\mathrm{mAb}$ cocktail, casirivimab and imdevimab, has demonstrated similar favorable outcomes in preventing hospitalizations among persons with mild to moderate COVD-19 at high risk for progression to severe disease [94, 95]. For persons with COVID-19 at risk for severe disease and not requiring hospitalization or supplemental oxygen, $\mathrm{mAb}$ seem to offer significant protection against progressing to severe disease.

\section{Antivirals}

Remdesivir is a nucleotide analog RNA polymerase inhibitor, and it is the only antiviral agent that has shown any benefit against COVID-19 in prospective studies. Multiple randomized clinical trials have showed some benefit in time to recovery, although mortality benefit is limited [96-98]. It is currently FDA-approved antiviral for treatment of COVID-19 and currently only for hospitalized persons. Other antivirals, such as lopinavir/ritonavir, and antimicrobials, such as hydroxychloroquine and azithromycin, have not shown benefit in randomized, controlled trials for treating COVID-19 despite retrospective, observational data of modest benefit [99-109]. A recent WHO-funded randomized clinical trial found no mortality benefit in severe COVID-19 among persons randomized to receive remdesivir, hydroxychloroquine, lopinavir, or interferon beta-1a [110]. The National Institutes of Health (NIH) and Infectious Diseases Society of America (IDSA) currently only recommend the use of remdesivir in persons with severe COVID-19 requiring hospitalization $[58,111]$. The WHO, on the contrary, does not recommend the use of remdesivir [112]. No other antimicrobials are currently recommended for the treatment of COVID-19.

\section{Corticosteroids and Immune Modulators}

Among severely ill persons with COVID-19 requiring supplemental oxygenation, dexamethasone does improve mortality and increase ventilator-free days [113-115]. Importantly, there is no benefit and may be a trend towards harm when using corticosteroids in early, mild to moderate COVID-19 without oxygen requirement. Baricitinib, a Janus kinase inhibitor, and tociliziumab, a mAb against IL-6, interrupt the overwhelming immune response that leads to adverse outcomes. These agents have shown some clinical benefit among persons with severe COVID-19 in randomized clinical trials, although their routine use is still being determined [116-119].

\section{Conclusion}

The COVID-19 pandemic is not the first pandemic of our era, and it is unlikely to be the last. It has caused incredible morbidity and mortality across the world. Controlling pandemics should be considered from the harm reduction approach to employ comprehensive prevention, realistic scale-up, early and accurate detection, and effective treatment. Lessons learned from one pandemic should be applied to other pandemics to help reduce morbidity and mortality.

\section{Declarations}

Conflict of Interest The authors declare no competing interests.

Human and Animal Rights and Informed consent This article does not contain any studies with human or animal subjects performed by any of the authors.

\section{References}

Papers of particular interest, published recently, have been highlighted as:

- Of importance

1. Centers for Disease Control and Prevention. Pneumocystis pneumonia-Los Angeles. MMWR Morb Mortal Wkly Rep. 1981;30(21):250-2.

2. Centers for Disease Control and Prevention. Kaposi's sarcoma and Pneumocystis pneumonia among homosexual men-New York City and California. MMWR Morb Mortal Wkly Rep. 1981;30(25):305-8.

3. World Health Organization: Pneumonia of unknown cause China. https://www.who.int/csr/don/05-january-2020-pneumonia-of-unkown-cause-china/en/ (2020). Accessed 2021 February.

4. World Health Organization: WHO Coronavirus Disease (COVID19) Dashboard. https://covid19.who.int/ (2021). Accessed February 42021.

5. Centers for Disease Control and Prevention: COVID Data Tracker. https://covid.cdc.gov/covid-data-tracker/\#datatrackerhome (2021). Accessed February 42021.

6. Hargreaves J, Davey C, Hargreaves J, Davey C, Auerbach J, Blanchard J, et al. Three lessons for the COVID-19 response from pandemic HIV. Lancet HIV. 2020;7(5):e309-e11. https://doi.org/ $10.1016 / \mathrm{S} 2352-3018(20) 30110-7$. 
7. Centers for Disease Control and Prevention. HIV Surveillance Report, 2018 (Updated). 2020.

8. Barbee LA, Dombrowski JC, Hermann S, Werth BJ, Ramchandani M, Ocbamichael N, et al. "Sex in the Time of COVID": clinical guidelines for sexually transmitted disease management in an era of social distancing. Sex Transm Dis. 2020;47(7):427-30. https://doi.org/10.1097/olq. 0000000000001194 .

9. Armstrong WS, Agwu AL, Barrette EP, Ignacio RB, Chang JJ, Colasanti JA, et al. Innovations in human immunodeficiency virus (HIV) care delivery during the coronavirus disease 2019 (COVID19) Pandemic: Policies to Strengthen the Ending the Epidemic Initiative-A Policy Paper of the Infectious Diseases Society of America and the HIV Medicine Association. Clin Infect Dis. 2021;72(1):9-14. https://doi.org/10.1093/cid/ciaa1532.

10. Tao J, Napoleon SC, Maynard MA, Almonte A, Silva E, Toma E, et al. Impact of the COVID-19 pandemic on sexually transmitted infection clinic visits. Sex Transm Dis. 2021;48(1):e5-7. https:// doi.org/10.1097/olq.0000000000001306.

11. National Coalition of STD Directors. COVID-19 \& The State of the STD Field. 2020.

12. Crane MA, Popovic A, Stolbach AI, Ghanem KG. Reporting of sexually transmitted infections during the COVID-19 pandemic. Sex Transm Infect. 2020.

13. Dorward J, Khubone T, Gate K, Ngobese H, Sookrajh Y, Mkhize S, et al. The impact of the COVID-19 lockdown on HIV care in 65 South African primary care clinics: an interrupted time series analysis. Lancet HIV. 2021. https://doi.org/10.1016/S2352-3018(20) 30359-3.

14. Spinelli MA, Hickey MD, Glidden DV, Nguyen JQ, Oskarsson JJ, Havlir D, et al. Viral suppression rates in a safety-net HIV clinic in San Francisco destabilized during COVID-19. AIDS. 2020;34(15):2328-31. https://doi.org/10.1097/qad. 0000000000002677 .

15. Blanco JL, Ambrosioni J, Garcia F, Martínez E, Soriano A, Mallolas J, et al. COVID-19 in patients with HIV: clinical case series. Lancet HIV. 2020;7(5):e314-e6. https://doi.org/10.1016/ S2352-3018(20)30111-9.

16. Shalev N, Scherer M, LaSota ED, Antoniou P, Yin MT, Zucker J, et al. Clinical characteristics and outcomes in people living with human immunodeficiency virus hospitalized for coronavirus disease 2019. Clin Infect Dis. 2020;71(16):2294-7. https://doi.org/ $10.1093 / \mathrm{cid} / \mathrm{ciaa} 635$.

17. Sigel K, Swartz T, Golden E, Paranjpe I, Somani S, Richter F, et al. Coronavirus 2019 and people living with human immunodeficiency virus: outcomes for hospitalized patients in New York City. Clin Iinfect Diseases : an official publication of the Infectious Diseases Society of America. 2020;71(11):2933-8. https://doi.org/10.1093/cid/ciaa880.

18. Cooper TJ, Woodward BL, Alom S, Harky A. Coronavirus disease 2019 (COVID-19) outcomes in HIV/AIDS patients: a systematic review. HIV Med. 2020;21(9):567-77. https://doi.org/10. 1111/hiv.12911.

19. Gervasoni C, Meraviglia P, Riva A, Giacomelli A, Oreni L, Minisci D, et al. Clinical features and outcomes of patients with human immunodeficiency virus with COVID-19. Clin Infect Dis. 2020;71(16):2276-8. https://doi.org/10.1093/cid/ciaa579.

20. Bhaskaran K, Rentsch CT, MacKenna B, Schultze A, Mehrkar A, Bates CJ, et al. HIV infection and COVID-19 death: a populationbased cohort analysis of UK primary care data and linked national death registrations within the OpenSAFELY platform. Lancet HIV. 2021;8(1):e24-32. https://doi.org/10.1016/S2352-3018(20) 30305-2.

21. Geretti AM, Stockdale AJ, Kelly SH, Cevik M, Collins S, Waters L, et al. Outcomes of coronavirus disease 2019 (COVID-19) Related hospitalization among people with human immunodeficiency virus (HIV) in the ISARIC World Health Organization (WHO) Clinical Characterization Protocol (UK): a prospective observational study. Clin Infect Dis. 2020. https://doi. org/10.1093/cid/ciaa1605.

22. Boulle A, Davies M-A, Hussey H, Ismail M, Morden E, Vundle Z, et al. Risk factors for COVID-19 death in a population cohort study from the Western Cape Province, South Africa. Clin Infect Diseases. 2020. https://doi.org/10.1093/cid/ciaa1198.

23. Dandachi D, Geiger G, Montgomery MW, Karmen-Tuohy S, Golzy M, Antar AAR, et al. Characteristics, comorbidities, and outcomes in a multicenter registry of patients with HIV and coronavirus disease-19. Clin Iinfect Diseases : an official publication of the Infectious Diseases Society of America. 2020. https://doi. org $/ 10.1093 /$ cid/ciaa1339.

24. Ssentongo P, Ssentongo AE, Heilbrunn ES, Ba DM, Chinchilli VM. Association of cardiovascular disease and 10 other preexisting comorbidities with COVID-19 mortality: a systematic review and meta-analysis. PLoS One. 2020;15(8):e0238215. https://doi.org/10.1371/journal.pone.0238215.

25. Childs K, Post FA, Norcross C, Ottaway Z, Hamlyn E, Quinn K, et al. Hospitalized patients with COVID-19 and human immunodeficiency virus: a case series. Clin Infect Dis. 2020;71(8):20212. https://doi.org/10.1093/cid/ciaa657.

26. Sachdev D, Mara E, Hsu L, Scheer S, Rutherford G, Enanoria W, et al. COVID-19 susceptibility and outcomes among people living with HIV in San Francisco. JAIDS J Acquired Immune Defic Syndromes. 2021;86(1):19-21. https://doi.org/10.1097/qai. 0000000000002531.

27. Pan D, Sze S, Minhas JS, Bangash MN, Pareek N, Divall P, et al. The impact of ethnicity on clinical outcomes in COVID-19: a systematic review. EClinicalMedicine. 2020;23:100404. https:// doi.org/10.1016/j.eclinm.2020.100404.

28. Meyerowitz EA, Kim AY, Ard KL, Basgoz N, Chu JT, Hurtado RM, et al. Disproportionate burden of coronavirus disease 2019 among racial minorities and those in congregate settings among a large cohort of people with HIV. Aids. 2020;34(12):1781-7. https://doi.org/10.1097/qad.0000000000002607.

29. Collins SE, Clifasefi SL, Logan DE, Samples LS, Somers JM, Marlatt GA. Current status, historical highlights, and basic principles of harm reduction. In: Harm reduction: pragmatic strategies for managing high-risk behaviors. 2nd ed. New York: The Guilford Press; 2012. p. 3-35.

30. Hawk M, Coulter RWS, Egan JE, Fisk S, Reuel Friedman M, Tula $\mathrm{M}$, et al. Harm reduction principles for healthcare settings. Harm Reduct J. 2017;14(1):70. https://doi.org/10.1186/s12954-0170196-4.

31. Eaton LA, Kalichman SC. Social and behavioral health responses to COVID-19: lessons learned from four decades of an HIV pandemic. J Behav Med. 2020;43(3):341-5. https://doi.org/10.1007/ s10865-020-00157-y.

32. Edelman EJ, Aoun-Barakat L, Villanueva M, Friedland G. Confronting another pandemic: lessons from HIV can inform our COVID-19 response. AIDS Behav. 2020;24(7):1977-9. https://doi.org/10.1007/s10461-020-02908-z.

33. Bandiera L, Pavar G, Pisetta G, Otomo S, Mangano E, Seck1 JR, et al. Face coverings and respiratory tract droplet dispersion. medRxiv. 2020:2020.08.11.20145086. doi: https://doi.org/10. 1101/2020.08.11.20145086.

34. Davies A, Thompson K-A, Giri K, Kafatos G, Walker J, Bennett A. Testing the efficacy of homemade masks: would they protect in an influenza pandemic? Disaster Med Public Health Prepared. 2013;7(4):413-8. https://doi.org/10.1017/dmp.2013.43.

35. Leung NHL, Chu DKW, Shiu EYC, Chan K-H, McDevitt JJ, Hau BJP, et al. Respiratory virus shedding in exhaled breath and efficacy of face masks. Nat Med. 2020;26(5):676-80. https://doi.org/ 10.1038/s41591-020-0843-2. 
36. Konda A, Prakash A, Moss GA, Schmoldt M, Grant GD, Guha S. Aerosol filtration efficiency of common fabrics used in respiratory cloth masks. ACS Nano. 2020;14(5):6339-47. https://doi.org/10. 1021/acsnano.0c03252.

37. Freedman DO, Wilder-Smith A. In-flight transmission of SARSCoV-2: a review of the attack rates and available data on the efficacy of face masks. J Travel Med. 2020;27(8). doi: https:// doi.org/10.1093/jtm/taaa178.

38. Hendrix MJ, Walde C, Findley K, Trotman R. Absence of apparent transmission of SARS-CoV-2 from two stylists after exposure at a hair salon with a universal face covering policy - Springfield, Missouri, May 2020. MMWR Morb Mortal Wkly Rep. 2020;69(28):930-2. https://doi.org/10.15585/mmwr.mm6928e2.

39. Schwartz KL, Murti M, Finkelstein M, Leis JA, Fitzgerald-Husek A, Bourns L, et al. Lack of COVID-19 transmission on an international flight. CMAJ. 2020;(15):192, E410. https://doi.org/10. 1503/cmaj. 75015.

40. Chu DK, Akl EA, Duda S, Solo K, Yaacoub S, Schünemann HJ, et al. Physical distancing, face masks, and eye protection to prevent person-to-person transmission of SARS-CoV-2 and COVID19: a systematic review and meta-analysis. Lancet. 2020;395(10242):1973-87. https://doi.org/10.1016/S01406736(20)31142-9.

41. Atrubin D, Wiese M, Bohinc B. An Outbreak of COVID-19 Associated with a recreational hockey game - Florida, June 2020. MMWR Morb Mortal Wkly Rep. 2020;69(41): 1492-3. https://doi.org/10.15585/mmwr.mm6941a4.

42. Hamner L, Dubbel P, Capron I, Ross A, Jordan A, Lee J, et al. High SARS-CoV-2 attack rate following exposure at a choir practice - Skagit County, Washington, March 2020. MMWR Morb Mortal Wkly Rep. 2020;69(19):606-10. https://doi.org/10. 15585/mmwr.mm6919e6.

43. Atherstone C, Siegel M, Schmitt-Matzen E, Sjoblom S, Jackson J, Blackmore C, et al. SARS-CoV-2 transmission associated with high school wrestling tournaments - Florida, December 2020January 2021. MMWR Morb Mortal Wkly Rep. 2021;70(4): 141-3. https://doi.org/10.15585/mmwr.mm7004e4.

44. Executive Order 13991. Protecting the federal workforce and requiring mask-wearing, 3 C.F.R. 7205-7208. 2021.

45. Centers for Disease Control and Prevention. Requirement for persons to wear masks while on conveyances and at transportation hubs. In: DHHS, editor.2021.

46. Lyu W, Wehby GL. Community use of face masks and COVID19: evidence from a natural experiment of state mandates In The US. Health Aff (Millwood). 2020;39(8):1419-25. https://doi.org/ 10.1377/hlthaff.2020.00818.

47. Joo H, Miller GF, Sunshine G, Gakh M, Pike J, Havers FP, et al. Decline in COVID-19 hospitalization growth rates associated with statewide mask mandates - 10 States, March-October 2020. MMWR Morb Mortal Wkly Rep. 2021;70(6):212-6. https://doi. org/10.15585/mmwr.mm7006e2.

48. Wang X, Ferro EG, Zhou G, Hashimoto D, Bhatt DL. Association between universal masking in a health care system and SARSCoV-2 positivity among health care workers. JAMA. 2020;324(7):703-4. https://doi.org/10.1001/jama.2020.12897.

49. Grant RM, Anderson PL, McMahan V, Liu A, Amico KR, Mehrotra M, et al. Uptake of pre-exposure prophylaxis, sexual practices, and HIV incidence in men and transgender women who have sex with men: a cohort study. Lancet Infect Dis. 2014;14(9):820-9. https://doi.org/10.1016/S1473-3099(14) 70847-3.

50. Grant RM, Lama JR, Anderson PL, McMahan V, Liu AY, Vargas L, et al. Preexposure chemoprophylaxis for HIV prevention in men who have sex with men. N Engl J Med. 2010;363(27): 2587-99. https://doi.org/10.1056/NEJMoa1011205.
51. McCormack S, Dunn DT, Desai M, Dolling DI, Gafos M, Gilson $\mathrm{R}$, et al. Pre-exposure prophylaxis to prevent the acquisition of HIV-1 infection (PROUD): effectiveness results from the pilot phase of a pragmatic open-label randomised trial. Lancet. 2016;387(10013):53-60. https://doi.org/10.1016/S01406736(15)00056-2.

52. Landovitz RJ. HPTN 083 FINAL RESULTS: Pre-exposure Prophylaxis containing long-acting injectable cabotegravir is safe and highly effective for cisgender men and transgender women who have sex with men. AIDS. Virtual 2020.

53. Abella BS, Jolkovsky EL, Biney BT, Uspal JE, Hyman MC, Frank I, et al. Efficacy and safety of hydroxychloroquine vs placebo for pre-exposure SARS-CoV-2 prophylaxis among health care workers: a randomized clinical trial. JAMA Intern Med. 2021;181(2):195-202. https://doi.org/10.1001/jamainternmed. 2020.6319.

54. Boulware DR, Pullen MF, Bangdiwala AS, Pastick KA, Lofgren $\mathrm{SM}$, Okafor EC, et al. A randomized trial of hydroxychloroquine as postexposure prophylaxis for Covid-19. N Engl J Med. 2020;383(6):517-25. https://doi.org/10.1056/NEJMoa2016638.

55. Mitjà $\mathrm{O}$, Corbacho-Monné $\mathrm{M}$, Ubals $\mathrm{M}$, Alemany $\mathrm{A}$, Suñer $\mathrm{C}$, Tebé $\mathrm{C}$, et al. A cluster-randomized trial of hydroxychloroquine for prevention of Covid-19. N Engl J Med. 2020;384(5):417-27. https://doi.org/10.1056/NEJMoa2021801.

56. Rajasingham R, Bangdiwala AS, Nicol MR, Skipper CP, Pastick $\mathrm{KA}$, Axelrod ML, et al. Hydroxychloroquine as pre-exposure prophylaxis for COVID-19 in healthcare workers: a randomized trial. Clin Iinfect Diseases : an official publication of the Infectious Diseases Society of America. 2020. https://doi.org/10.1093/cid/ ciaal571.

57. Revollo B, Tebe C, Peñafiel J, Blanco I, Perez-Alvarez N, Lopez $\mathrm{R}$, et al. Hydroxychloroquine pre-exposure prophylaxis for COVID-19 in healthcare workers. J Antimicrob Chemother. 2020;76:827-9. https://doi.org/10.1093/jac/dkaa477.

58. National Institutes of Health. COVID-19 treatment guidelines panel. Coronavirus Disease 2019 (COVID-19) Treatment Guidelines. 2021. Using the most up-to-date data, the NIH develops and publishes evidencebased guidelines for the treatment of COVID-19.

59. Anderson EJ, Rouphael NG, Widge AT, Jackson LA, Roberts PC, Makhene M, et al. Safety and Immunogenicity of SARS-CoV-2 mRNA-1273 vaccine in older adults. N Engl J Med. 2020;383(25):2427-38. https://doi.org/10.1056/ NEJMoa2028436.

60. Baden LR, El Sahly HM, Essink B, Kotloff K, Frey S, Novak R, et al. Efficacy and safety of the mRNA-1273 SARS-CoV-2 vaccine. N Engl J Med. 2020;384(5):403-16. https://doi.org/10.1056/ NEJMoa2035389.

61. Polack FP, Thomas SJ, Kitchin N, Absalon J, Gurtman A, Lockhart S, et al. Safety and efficacy of the BNT162b2 mRNA Covid-19 vaccine. N Engl J Med. 2020;383(27):2603-15. https://doi.org/10.1056/NEJMoa2034577. This multinational, randomized, placebo-controlled trial demonstrated robust protection against COVID-19 after completing a two-dose series of the BNT-162b2 mRNA vaccine.

62. Sadoff J, Le Gars M, Shukarev G, Heerwegh D, Truyers C, de Groot AM, et al. Interim results of a phase 1-2a trial of Ad26.COV2.S Covid-19 vaccine. N Engl J Med. 2021. https:// doi.org/10.1056/NEJMoa2034201.

63. Johnson and Johnson. Johnson \& Johnson announces single-shot Janssen COVID-19 vaccine candidate met primary endpoints in interim analysis of its phase 3 ENSEMBLE trial. 2021.

64. Voysey M, Clemens SAC, Madhi SA, Weckx LY, Folegatti PM, Aley PK, et al. Safety and efficacy of the ChAdOx1 nCoV-19 vaccine (AZD1222) against SARS-CoV-2: an interim analysis of four randomised controlled trials in Brazil, South Africa, and 
the UK. Lancet. 2021;397(10269):99-111. https://doi.org/10. 1016/S0140-6736(20)32661-1.

65. Logunov DY, Dolzhikova IV, Shcheblyakov DV, Tukhvatulin AI, Zubkova OV, Dzharullaeva AS, et al. Safety and efficacy of an rAd26 and rAd5 vector-based heterologous prime-boost COVID-19 vaccine: an interim analysis of a randomised controlled phase 3 trial in Russia. Lancet. 2021. https://doi.org/10. 1016/S0140-6736(21)00234-8.

66. Ojikutu BO, Stephenson KE, Mayer KH, Emmons KM. Building trust in COVID-19 vaccines and beyond through authentic community investment. Am J Public Health. 2020;111:e1-3. https:// doi.org/10.2105/ajph.2020.306087.

67. Nguyen K, Srivastav A, Razzaghi H, et al. Vaccination intent, perceptions, and reasons for not vaccinating among groups prioritized for early vaccination - United States, September and December 2020. MMWR Morb Mortal Wkly Rep. 2021. https:// doi.org/10.15585/mmwr.mm7006e3external.

68. Bogart LM, Ojikutu BO, Tyagi K, Klein DJ, Mutchler MG, Dong L, et al. COVID-19 related medical mistrust, health impacts, and potential vaccine hesitancy among Black Americans living with HIV. JAIDS J Acquired Immune Defic Syndromes. 2021;86(2): 200-7. https://doi.org/10.1097/qai.0000000000002570.

69. Hanson KE, Caliendo AM, Arias CA, Hayden MK, Englund JA, Lee MJ, et al. The infectious diseases society of America guidelines on the diagnosis of COVID-19: molecular diagnostic testing. Clin Iinfect Diseases : an official publication of the Infectious Diseases Society of America. 2021. https://doi.org/10.1093/cid/ ciab048. These guidelines, developed by the Infectious Diseases Society of America, provide evidence-based recommendations for the diagnosis of COVID-19.

70. Dinnes J, Deeks JJ, Adriano A, Berhane S, Davenport C, Dittrich $\mathrm{S}$, et al. Rapid, point-of-care antigen and molecular-based tests for diagnosis of SARS-CoV-2 infection. Cochrane Database of Syst Rev 2020(8). doi: https://doi.org/10.1002/14651858.CD013705.

71. Pilarowski G, Lebel P, Sunshine S, Liu J, Crawford E, Marquez C, et al. Performance characteristics of a rapid severe acute respiratory syndrome coronavirus 2 antigen detection assay at a public plaza testing site in San Francisco. J Infect Dis. 2021;223:113944. https://doi.org/10.1093/infdis/jiaa802.

72. Prince-Guerra JL, Almendares O, Nolen LD, Gunn JKL, Dale AP, Buono SA, et al. Evaluation of Abbott BinaxNOW rapid antigen test for SARS-CoV-2 infection at two community-based testing sites - Pima County, Arizona, November 3-17, 2020. MMWR Morb Mortal Wkly Rep. 2021;70(3):100-5. https://doi.org/10. 15585/mmwr.mm7003e3.

73. Okoye NC, Barker AP, Curtis K, Orlandi RR, Snavely EA, Wright $\mathrm{C}$, et al. Performance characteristics of BinaxNOW COVID-19 antigen card for screening asymptomatic individuals in a university setting. J Clin Microbiol. 2021;59. https://doi.org/ 10.1128/jcm.03282-20.

74. Pilarowski G, Marquez C, Rubio L, Peng J, Martinez J, Black D, et al. Field performance and public health response using the BinaxNOW TM Rapid SARS-CoV-2 antigen detection assay during community-based testing. Clin Iinfect Diseases : an official publication of the Infectious Diseases Society of America. 2020. https://doi.org/10.1093/cid/ciaa1890.

75. Perchetti GA, Huang ML, Mills MG, Jerome KR, Greninger AL. Analytical sensitivity of the Abbott BinaxNOW COVID-19 Ag CARD. J Clin Microbiol. 2020. https://doi.org/10.1128/jcm. 02880-20.

76. Hanson KE, Caliendo AM, Arias CA, Englund JA, Hayden MK, Lee MJ, et al. Infectious diseases society of America guidelines on the diagnosis of COVID-19: serologic testing. Clin Iinfect Diseases : an official publication of the Infectious Diseases Society of America. 2020. https://doi.org/10.1093/cid/ciaa1343.
77. Hawk ME, Chung A, Creasy SL, Egan JE. A scoping review of patient preferences for HIV self-testing services in the United States: implications for harm reduction. Patient Prefer Adherence. 2020;14:2365-75. https://doi.org/10.2147/ppa. S251677.

78. Food and Drug Administration. Coronavirus (COVID-19) update: FDA authorizes first COVID-19 test for self-testing at home. 2020.

79. Lucira Health. Lucira COVID-19 All-In-One Test Kit Instructions for Use. 2020.

80. Abbott Laboratories. BinaxNOW COVID-19 AG Card Home Test (PN 195-100) - instructions for use. 2020.

81. Food and Drug Administration. Coronavirus (COVID-19) update: FDA issues new authorization for the BinaxNOW COVID-19 Ag Card Home Test. 2020.

82. Ellume. Ellume's COVID-19 home test shows $96 \%$ accuracy in multi-site US clinical study. 2020.

83. Ellume. COVID-19 home test product overview for healthcare professionals. 2020.

84. Food and Drug Administration. Coronavirus (COVID-19) update: FDA authorizes antigen test as first over-the-counter fully at-home diagnostic test for COVID-19. 2020.

85. Saag MS, Benson CA, Gandhi RT, Hoy JF, Landovitz RJ, Mugavero MJ, et al. Antiretroviral drugs for treatment and prevention of hiv infection in adults: 2018 recommendations of the international antiviral society-usa panel. JAMA. 2018;320(4): 379-96. https://doi.org/10.1001/jama.2018.8431.

86. Emu B, Fessel J, Schrader S, Kumar P, Richmond G, Win S, et al. Phase 3 study of ibalizumab for multidrug-resistant HIV-1. N Engl J Med. 2018;379(7):645-54. https://doi.org/10.1056/ NEJMoa1711460.

87. Chen P, Nirula A, Heller B, Gottlieb RL, Boscia J, Morris J, et al. SARS-CoV-2 neutralizing antibody LY-CoV555 in outpatients with Covid-19. N Engl J Med. 2021;384(3):229-37. https://doi. org/10.1056/NEJMoa2029849.

88. An EUA for Bamlanivimab. a monoclonal antibody for COVID19. JAMA. 2020. https://doi.org/10.1001/jama.2020.24415.

89. Mahase E. Covid-19: FDA authorises neutralising antibody bamlanivimab for non-admitted patients. BMJ. 2020;371: m4362. https://doi.org/10.1136/bmj.m4362.

90. ACTIV-3/TICO LY-CoV555 Study Group. A neutralizing monoclonal antibody for hospitalized patients with Covid-19. N Engl J Med. 2020. https://doi.org/10.1056/NEJMoa2033130.

91. Gottlieb RL, Nirula A, Chen P, Boscia J, Heller B, Morris J, et al. Effect of bamlanivimab as monotherapy or in combination with etesevimab on viral load in patients with mild to moderate COVID-19: a randomized clinical trial. Jama. 2021;325:632-44. https://doi.org/10.1001/jama.2021.0202.

92. Eli Lilly and Company. New data show treatment with Lilly's neutralizing antibodies bamlanivimab (LY-CoV555) and etesevimab (LY-CoV016) together reduced risk of COVID-19 hospitalizations and death by 70 percent. 2021.

93. Eli Lilly and Company. Lilly's bamlanivimab (LY-CoV555) administered with etesevimab (LY-CoV016) receives FDA emergency use authorization for COVID-19. 2021.

94. An EUA. for casirivimab and imdevimab for COVID-19. Med Lett Drugs Ther. 2020;62(1614):201-2.

95. Weinreich DM, Sivapalasingam S, Norton T, Ali S, Gao H, Bhore $\mathrm{R}$, et al. REGN-COV2, a neutralizing antibody cocktail, in outpatients with Covid-19. N Engl J Med. 2021;384(3):238-51. https:// doi.org/10.1056/NEJMoa2035002.

96. Beigel JH, Tomashek KM, Dodd LE, Mehta AK, Zingman BS, Kalil AC, et al. Remdesivir for the treatment of Covid-19 - final report. N Engl J Med. 2020;383(19):1813-26. https://doi.org/10. 1056/NEJMoa2007764. This double-blinded, randomized, placebo-controlled study showed that remdesivir shortened 
the time to recovery among persons with severe COVID-19 requiring hospitalization.

97. Spinner CD, Gottlieb RL, Criner GJ, Arribas López JR, Cattelan AM, Soriano Viladomiu A, et al. Effect of remdesivir vs standard care on clinical status at 11 days in patients with moderate COVID-19: a randomized clinical trial. Jama. 2020;324(11): 1048-57. https://doi.org/10.1001/jama.2020.16349.

98. Wang Y, Zhang D, Du G, Du R, Zhao J, Jin Y, et al. Remdesivir in adults with severe COVID-19: a randomised, double-blind, placebo-controlled, multicentre trial. Lancet (London, England). 2020;395(10236):1569-78. https://doi.org/10.1016/s01406736(20)31022-9.

99. Cavalcanti AB, Zampieri FG, Rosa RG, Azevedo LCP, Veiga $\mathrm{VC}$, Avezum A, et al. Hydroxychloroquine with or without Azithromycin in Mild-to-Moderate Covid-19. N Engl J Med. 2020;383(21):2041-52. https://doi.org/10.1056/ NEJMoa2019014.

100. Furtado RHM, Berwanger O, Fonseca HA, Corrêa TD, Ferraz LR, Lapa MG, et al. Azithromycin in addition to standard of care versus standard of care alone in the treatment of patients admitted to the hospital with severe COVID-19 in Brazil (COALITION II): a randomised clinical trial. Lancet (London, England). 2020;396(10256):959-67. https://doi.org/10.1016/s01406736(20)31862-6.

101. Geleris J, Sun Y, Platt J, Zucker J, Baldwin M, Hripcsak G, et al. Observational study of hydroxychloroquine in hospitalized patients with Covid-19. N Engl J Med. 2020;382(25):2411-8. https://doi.org/10.1056/NEJMoa2012410.

102. Horby P, Mafham M, Linsell L, Bell JL, Staplin N, Emberson JR, et al. Effect of hydroxychloroquine in hospitalized patients with COVID-19: preliminary results from a multi-centre, randomized, controlled trial. medRxiv. 2020:2020.07.15.20151852. doi: https://doi.org/10.1101/2020.07.15.20151852.

103. Rosenberg ES, Dufort EM, Udo T, Wilberschied LA, Kumar J, Tesoriero J, et al. Association of treatment with hydroxychloroquine or azithromycin with in-hospital mortality in patients with COVID-19 in New York State. Jama. 2020;323(24):2493-502. https://doi.org/10.1001/jama.2020. 8630.

104. Skipper CP, Pastick KA, Engen NW, Bangdiwala AS, Abassi M, Lofgren SM, et al. Hydroxychloroquine in nonhospitalized adults with early COVID-19 : a randomized trial. Ann Intern Med. 2020;173(8):623-31. https://doi.org/10.7326/m20-4207.

105. Arshad S, Kilgore P, Chaudhry ZS, Jacobsen G, Wang DD, Huitsing K, et al. Treatment with hydroxychloroquine, azithromycin, and combination in patients hospitalized with COVID-19. Int J Infect Diseases : IJID : official publication of the International Society for Infectious Diseases. 2020;97:396403. https://doi.org/10.1016/j.ijid.2020.06.099.

106. Catteau L, Dauby N, Montourcy M, Bottieau E, Hautekiet J, Goetghebeur E, et al. Low-dose hydroxychloroquine therapy and mortality in hospitalised patients with COVID-19: a nationwide observational study of 8075 participants. Int J Antimicrob Agents. 2020;56(4):106144. https://doi.org/10.1016/j.ijantimicag. 2020.106144.

107. Mikami T, Miyashita H, Yamada T, Harrington M, Steinberg D, Dunn A, et al. Risk factors for mortality in patients with COVID19 in New York City. J Gen Intern Med. 2021;36(1):17-26. https://doi.org/10.1007/s11606-020-05983-z.
108. Magagnoli J, Narendran S, Pereira F, Cummings TH, Hardin JW, Sutton SS, et al. Outcomes of hydroxychloroquine usage in United States veterans hospitalized with COVID-19. Med (N Y). 2020;1(1):114-27.e3. https://doi.org/10.1016/j.medj.2020.06. 001.

109. Cao B, Wang Y, Wen D, Liu W, Wang J, Fan G, et al. A trial of lopinavir-ritonavir in adults hospitalized with severe Covid-19. N Engl J Med. 2020;382(19):1787-99. https://doi.org/10.1056/ NEJMoa2001282.

110. WHO Solidarity Trial Consortium. Repurposed antiviral drugs for Covid-19 - Interim WHO Solidarity Trial Results. N Engl J Med. 2020;384(6):497-511. https://doi.org/10.1056/NEJMoa2023184.

111. Bhimraj A, Morgan RL, Shumaker AH, Lavergne V, Baden LR, Cheng VC, et al.: Infectious diseases society of America guidelines on the treatment and management of patients with COVID19. https:/www.idsociety.org/practice-guideline/covid-19-guideline-treatment-and-management/ (2021). Accessed February 16, 20212021.

112. Organization WH. COVID-19 Clinical Management Living Guidance. 2021.

113. The RECOVERY Collaborative Group. Dexamethasone in hospitalized patients with Covid-19 - Preliminary Report. N Engl J Med. 2020;384:693-704. https://doi.org/10.1056/ NEJMoa2021436. This open-label trial demonstrated 28-day mortality benefit of dexamethasone compared to usual care among persons hospitalized with COVID-19.

114. Tomazini BM, Maia IS, Cavalcanti AB, Berwanger O, Rosa RG, Veiga VC, et al. Effect of dexamethasone on days alive and ventilator-free in patients with moderate or severe acute respiratory distress syndrome and COVID-19: The CoDEX randomized clinical trial. Jama. 2020;324(13):1307-16. https://doi.org/10. 1001/jama.2020.17021.

115. The WHO. Rapid Evidence Appraisal for COVID-19 Therapies Working Group. Association between administration of systemic corticosteroids and mortality among critically ill patients with COVID-19: a meta-analysis. JAMA. 2020;324(13):1330-41. https://doi.org/10.1001/jama.2020.17023.

116. Gordon AC, Mouncey PR, Al-Beidh F, Rowan KM, Nichol AD, Arabi YM, et al. Interleukin-6 receptor antagonists in critically ill patients with Covid-19 - preliminary report. medRxiv. 2021: 2021.01.07.21249390. doi: https://doi.org/10.1101/2021.01.07. 21249390.

117. Salama C, Han J, Yau L, Reiss WG, Kramer B, Neidhart JD, et al. Tocilizumab in patients hospitalized with Covid-19 pneumonia. $\mathrm{N}$ Engl J Med. 2020;384(1):20-30. https://doi.org/10.1056/ NEJMoa2030340.

118. Salvarani C, Dolci G, Massari M, Merlo DF, Cavuto S, Savoldi L, et al. Effect of tocilizumab vs standard care on clinical worsening in patients hospitalized with COVID-19 pneumonia: a randomized clinical trial. JAMA Intern Med. 2021;181(1):24-31. https://doi. org/10.1001/jamainternmed.2020.6615.

119. Kalil AC, Patterson TF, Mehta AK, Tomashek KM, Wolfe CR, Ghazaryan V, et al. Baricitinib plus remdesivir for hospitalized adults with Covid-19. N Engl J Med. 2020;384:795-807. https:// doi.org/10.1056/NEJMoa2031994.

Publisher's Note Springer Nature remains neutral with regard to jurisdictional claims in published maps and institutional affiliations. 